\title{
A Retrospective Analysis of Primary Gastrointestinal Non-Hodgkin Lymphomas: Clinical Features, Prognostic Factors and Treatment Outcomes
}

This article was published in the following Dove Press journal: OncoTargets and Therapy

\section{Chen Tian (D) \\ Yueyang Li (D) \\ Zehui Chen}

Department of Hematology, Tianjin Medical University Cancer Institute and Hospital, National Clinical Research Center for Cancer, Key Laboratory of Cancer Prevention and Therapy, Tianjin 300060, People's Republic of China
Correspondence: Chen Tian Email tcgirl200।@sina.com
Introduction: Primary gastrointestinal non-Hodgkin lymphoma (PGIL) is a rare hematopoietic malignancy with limited data to guide management.

Methods: We analyzed the clinical characteristics and survival of 219 newly diagnosed PGIL patients.

Results: Our single-center data showed that the incidence rate of primary gastric lymphoma (PGL) was higher than that of primary intestine lymphoma (PIL). Most PGIL was B-cell originated and DLBCL was the most common pathological type both in PGL and PIL group. Univariate and multivariate analysis showed that IPI score and pathology were independent prognostic factors. The overall survival (OS) and progression-free survival (PFS) of patients with MYC rearrangement were much shorter compared to patients without MYC rearrangement indicating that MYC translocation was related to decreased survival. Neither OS nor PFS differed between patients who received chemotherapy with or without surgery. However, patients who received surgery alone had a poor prognosis.

Conclusion: Chemotherapy is the front-line treatment for PGIL while surgery was conducted to relieve tumor-related complications or make diagnosis. MYC rearrangement predicted poor prognosis of PGIL patients.

Keywords: primary gastrointestinal lymphomas, prognosis, MYC rearrangement

\section{Background}

Primary gastrointestinal non-Hodgkin lymphoma (PGIL) is the most common type of extranodal lymphomas, accounting for $30 \%$ to $40 \%$ of extranodal lymphomas. It is reported that diffuse large B-cell lymphoma (DLBCL) is the most common histological subtype. Treatments on PGIL are still controversial. The general consensus is systemic chemotherapy combined with local-therapy options such as radiotherapy or surgery if the local lesions are too large to affect organ function. Surgical treatment is usually indicated for intestine lymphomas for intestinal obstruction or intestinal perforation only. Helicobacter pylori (H.P.) eradication therapy is the first-line treatment of gastric mucosa-associated lymphoid tissue (MALT) lymphoma if the patient has H.P. infection. Therefore, the optimal treatment strategy for PGIL is still not established. To learn more about the characteristics of PGIL and find out the prognostic factors for PGIL, we perform a retrospective clinical analysis of PGIL containing 219 PGIL cases from our single center. 


\section{Methods}

\section{Patients}

This study was subject to approval by the Research Ethics Committee of Tianjin Medical University Cancer Institute and Hospital. All experiment protocols were approved by Tianjin Medical University Cancer Institute and Hospital and performed in accordance with relevant guidelines and regulations. Informed consent was obtained from all participants or, if participants were under 18, from a parent and/or legal guardian. PGIL cases were collected from Jan 2008 to Dec 2017. The diagnosis of PGIL was based on the 2008 WHO classification. Data concerning demographic, clinical, endoscopic features, biological and histological features, as well as treatments and clinical outcomes were recorded. A total of 219 patients were enrolled and observed until death. The follow-up data, including endpoint of collection, reasons for ending, and living status, were collected. The deadline for follow-up was Sep 30 2019. According to WHO criteria, the response evaluation was divided into complete response (CR), partial response (PR), stable disease (SD) and progressive disease (PD).

\section{Immunohistochemical Staining}

Tumor tissues were fixed in 10\% buffered formalin and paraffin-embedded (FFPE), and then stained with hematoxylin and eosin (HE) or immunohistochemical (IHC) stains. The primary antibodies were antibodies against CD3 (Clone SP7), c-MYC (Clone Y69, Abcam), CD10 (Clone 56C6, Ventana, Tucson, AZ), BCL2 (Clone 124), BCL6 (Clone PG-B6P), CD20 (Clone L26), Ki-67 (Clone MIB-1), and MUM1 (Clone Mum1P, Dako, Glostrup, Denmark). The cutoff values for positivity were defined as $\geq 40 \%$ for BCL6 and MYC staining and $\geq 70 \%$ staining for BCL2.

\section{Realtime RT-PCR Analyses and FISH}

Genomic DNA was extracted using a QIAamp DNA FFPE Tissue Kit (Qiagen, Valencia, CA) and then amplified using the primers for the MYC gene, which is forward: 5'-AT CACAGCCCTCACTCAC-3', reverse: 5'-ACAGATTCC ACAAGGTGC-3'. The PCR products were Sangersequenced using the forward and reverse primers.

FISH was performed on 3- $\mu \mathrm{m}$ tissue microarray sections using dual-color break-apart probes (c-MYC/8q24) (Abbott Laboratories, Des Plaines, IL) according to the manufacturer's instructions using a HybriMax hybridization system (no.1502080). The signals from 100 nonoverlapping nuclei were analyzed. Positivity was determined as a $\geq 15 \%$ threshold for split or fusion signal and a $30 \%$ threshold for extra copy signal (defined as copy number $\geq 3$ per cell).

\section{Statistical Analysis}

Statistical analysis was performed using SPSS. Overall survival (OS) was calculated from the date of diagnosis until the date of death from any cause or until the date of final follow-up. Progression-free survival (PFS) was determined for responders from the time of diagnosis until progression from any cause. The significance of the difference between survival curves was calculated by the Log-rank test. Groupwise comparisons of the distributions of variables were performed with the generalized Wilcoxon test. The Cox proportional hazards regression model was used in multivariate analysis to compare the factors proven to be statistically significant or to demonstrate a trend in the univariate analysis. A $P$-value $<0.05$ was considered significantly different.

\section{Results}

\section{Clinical Characteristics}

Of the 219 patients' retrospective cohort, 126 patients were males and 93 patients were females. The ratio of males to females was 1.35:1. The average age was 56 years old, and the median age was 57 years old. The highest incidence was found in the 55-65 age group with 38.4\% (84/219), followed by 48 cases $(21.9 \%)$ in the age group over 65 years old. The lowest incidence was in the age group younger than 20 years old, accounting for $1.4 \%$. According to the International Prognostic Index (IPI), 182 cases (83.1\%) scored 0-2 and 37 cases (16.9\%) scored 3-5. All patients were examined for Helicobacter pylori infection (including pathological biopsy, serum Helicobacter pylori antibody, ${ }^{13} \mathrm{C}$-urea breath test), of which $23(10 \%)$ were positive for Helicobacter pylori (Table 1).

Of the 219 patients, $205(93.6 \%)$ patients were B-cell origin and $14(6.4 \%)$ patients were T-cell origin. Among them, 131 cases (59.8\%) were diffuse large B-cell lymphoma (DLBCL), 25 cases (11.4\%) were mucosa-associated lymphoid tissue (MALT) lymphoma, followed by mantle cell lymphoma (MCL), follicular cell lymphoma (FL), Burkitt lymphoma and other B-cell lymphoma (Figure 1). Patients with T-cell 
Table I Clinical Features of 219 Patients with PGI-NHL

\begin{tabular}{|c|c|c|c|c|c|c|c|c|}
\hline \multicolumn{2}{|l|}{ Index } & \multicolumn{2}{|l|}{ Stomach } & \multicolumn{2}{|l|}{ Intestine } & \multirow[t]{2}{*}{ Total } & \multirow[t]{2}{*}{$\chi^{2}$} & \multirow[t]{2}{*}{$P$ value } \\
\hline & & Number & Ratio\% & Number & Ratio\% & & & \\
\hline Sex & $\begin{array}{l}\text { Male } \\
\text { Female }\end{array}$ & $\begin{array}{l}76 \\
64\end{array}$ & $\begin{array}{l}60.3 \\
68.8\end{array}$ & $\begin{array}{l}50 \\
29\end{array}$ & $\begin{array}{l}39.7 \\
31.2\end{array}$ & $\begin{array}{l}126 \\
93\end{array}$ & 1.676 & 0.195 \\
\hline Age & $\begin{array}{l}<60 \\
\geqq 60\end{array}$ & $\begin{array}{l}75 \\
65\end{array}$ & $\begin{array}{l}60.5 \\
68.4\end{array}$ & $\begin{array}{l}49 \\
30\end{array}$ & $\begin{array}{l}39.5 \\
31.6\end{array}$ & $\begin{array}{l}124 \\
95\end{array}$ & 1.469 & 0.225 \\
\hline IPI & $\begin{array}{l}0-2 \\
3-5\end{array}$ & $\begin{array}{l}115 \\
25\end{array}$ & $\begin{array}{l}63.2 \\
67.6\end{array}$ & $\begin{array}{l}67 \\
12\end{array}$ & $\begin{array}{l}36.8 \\
32.4\end{array}$ & $\begin{array}{l}182 \\
37\end{array}$ & 0.256 & 0.613 \\
\hline Pathology & $\begin{array}{l}\text { Bcell origin } \\
\text { Tcell origin }\end{array}$ & $\begin{array}{l}135 \\
5\end{array}$ & $\begin{array}{l}65.9 \\
35.7\end{array}$ & $\begin{array}{l}70 \\
9\end{array}$ & $\begin{array}{l}34.1 \\
64.3\end{array}$ & $\begin{array}{l}205 \\
14\end{array}$ & 5.162 & 0.023 \\
\hline Hp test & $\begin{array}{l}\text { Positive } \\
\text { Negative }\end{array}$ & $\begin{array}{l}20 \\
120\end{array}$ & $\begin{array}{l}90.9 \\
60.9\end{array}$ & $\begin{array}{l}3 \\
77\end{array}$ & $\begin{array}{l}9.1 \\
39.0\end{array}$ & $\begin{array}{l}23 \\
197\end{array}$ & 7.721 & 0.005 \\
\hline Lugano stage & $\begin{array}{l}\text { I-II } \\
\text { III-IV }\end{array}$ & $\begin{array}{l}88 \\
54\end{array}$ & $\begin{array}{l}72.9 \\
53.5\end{array}$ & $\begin{array}{l}32 \\
47\end{array}$ & $\begin{array}{l}27.1 \\
46.5\end{array}$ & $\begin{array}{l}118 \\
101\end{array}$ & 8.896 & 0.003 \\
\hline Ann Arbor stage & $\begin{array}{l}\text { I-II } \\
\text { III-IV }\end{array}$ & $\begin{array}{l}90 \\
50\end{array}$ & $\begin{array}{l}70.9 \\
54.3\end{array}$ & $\begin{array}{l}37 \\
42\end{array}$ & $\begin{array}{l}29.1 \\
45.7\end{array}$ & $\begin{array}{l}127 \\
92\end{array}$ & 6.313 & 0.012 \\
\hline
\end{tabular}

lymphoma include peripheral T-cell lymphoma (PTCL), enteropathy-associated T-cell lymphoma (EATL), extranodal NK/T-cell lymphoma and other T-cell lymphoma (Table 2).
Stomach was the site mostly to be involved (63.6\%) followed by small intestinal (14.6\%) and large intestinal $(11 \%)$. Infringement of ileocecal and multiple involved sites was still rare in clinics.

\section{Incidence site}

Stomach $(63.9 \%)$

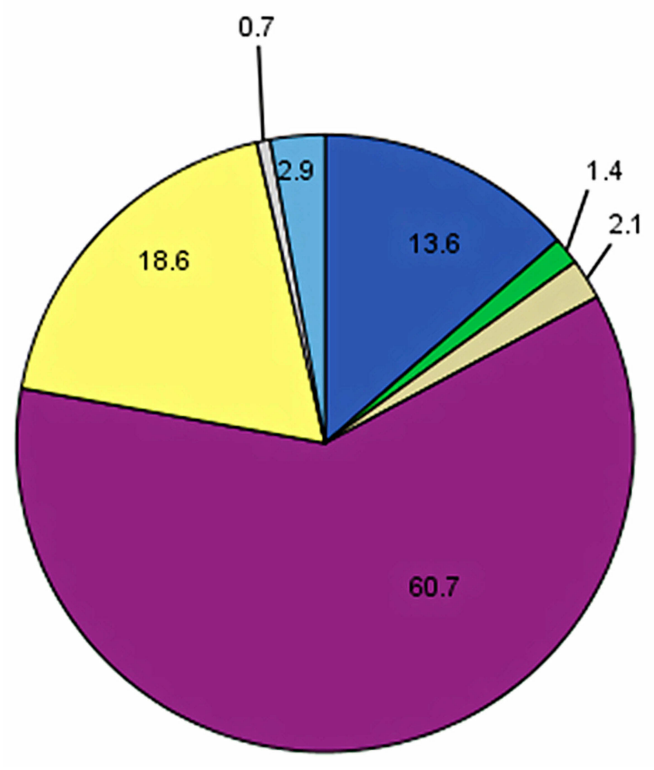

Histological type

Intestine $(36.1 \%)$

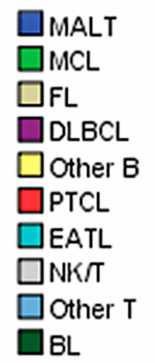

$\square \mathrm{BL}$

Figure I Incidence rate of subtypes of lymphoma.

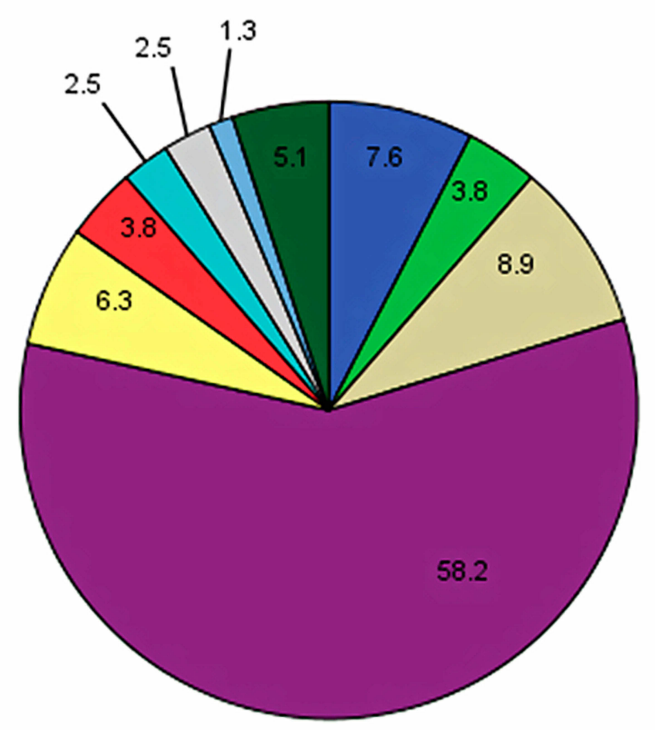


Table 2 Pathology of Different Sites of Lesion

\begin{tabular}{|c|c|c|c|c|c|}
\hline Pathology & Stomach (\%) & Small Intestine (\%) & Ileocecal Region (\%) & Large Intestine (\%) & Multiple Involvement (\%) \\
\hline \multicolumn{6}{|l|}{ B-cell lymphoma } \\
\hline MALT & $20(80.0)$ & I (4.0) & $0(0.0)$ & $2(8.0)$ & $2(8.0)$ \\
\hline $\mathrm{MCL}$ & I (20.0) & $0(0.0)$ & I (20.0) & I (20.0) & $2(40.0)$ \\
\hline FL & $3(30.0)$ & $6(60.0)$ & $0(0.0)$ & $I(10.0)$ & $0(0.0)$ \\
\hline DLBCL & $83(63.4)$ & $19(14.5)$ & $10(7.6)$ & $13(9.9)$ & $6(4.6)$ \\
\hline BL & $0(0.0)$ & $0(0.0)$ & $0(0.0)$ & $3(75.0)$ & I (25.0) \\
\hline Other-B & $26(83.9)$ & $4(12.9)$ & $\mathrm{I}(3.2)$ & $0(0.0)$ & $0(0.0)$ \\
\hline \multicolumn{6}{|l|}{ T-cell lymphoma } \\
\hline PTCL & $0(0.0)$ & I (33.3) & $0(0.0)$ & I (33.3) & I (33.3) \\
\hline EATL & $0(0.0)$ & I (50.0) & $0(0.0)$ & I (50.0) & $0(0.0)$ \\
\hline $\mathrm{NK} / \mathrm{T}$ & I (33.3) & $0(0.0)$ & $0(0.0)$ & $2(66.7)$ & $0(0.0)$ \\
\hline Other-T & $4(80.0)$ & $0(0.0)$ & I (20.0) & $0(0.0)$ & $0(0.0)$ \\
\hline
\end{tabular}

\section{Prognosis Factors of PGI-NHL Patients}

The median follow-up time was 74 months (range: 32-117 months). The median PFS was 32 months (95\% CI: 30.56-38.36, range: 1-108 months), and the median OS was 54 months (95\% CI: 48.35-56.04, range: 1-117 months). The 3-year PFS and OS estimates for all patients were $24.7 \%$ and $42.3 \%$, respectively. The patients were divided into gastric and intestinal groups according to the location of the lesions. The age, sex, IPI score, pathology, clinical stage (Ann Arbor/Lugano staging system) and HP infection of the two groups were compared. The results showed that primary gastric patients were mainly B-cell nonHodgkin lymphoma with high HP infection rate, while T-cell lymphoma was more common in the intestinal group. In addition, Lugano staging system $(\mathrm{P}=0.003)$ is more valuable for the prognosis of PGI-NHL patients compared to Ann Arbor staging system ( $\mathrm{P}=0.012)$.

There were no significant differences in PFS $(\mathrm{P}=0.621)$ and $\mathrm{OS}(\mathrm{P}=0.549)$ between gastric (OS 80.550 months, $95 \%$ CI: 72.186-88.914; PFS 72.738 months, $95 \%$ CI: 64.570 80.905) and intestinal (OS 72.742, 95\% CI: 65.354-90.130; PFS 64.069, 95\% CI: 52.039-76.100) groups. However, the OS for B-cell patients (80.916 months, 95\% CI: 72.18688.914) was significantly longer compared with those of T-cell patients (69.978 months, 95\% CI: 33.093-106.862) $(\mathrm{P}=0.009)$. The PFS $(\mathrm{P}=0.023)$ and $\mathrm{OS}(\mathrm{P}=0.003)$ of patients with high IPI score (OS 69.478 months, 95\% CI: 47.66691.289; PFS 37.158 months, 95\% CI: 25.716-48.599) were shorter than those with low IPI score (OS 75.524 months, 95\% CI: 69.145-81.904; PFS 68.157 months, 95\% CI: 59.934-76.380), indicating that high IPI score and T-cell origin were related with poor prognosis. Multivariate analysis showed that stage I/II and stage III/IV according to both Ann Arbor and Lugano staging system had no effect on PFS and OS, as shown in Table 3.

B-cell-derived non-Hodgkin's lymphoma can be divided into two groups according to the malignant degree: invasive lymphoma and inert lymphoma. DLBCL, MCL and $\mathrm{BL}$ were categorized as invasive lymphoma, while inert lymphoma included FL and MALT lymphoma. Patients with inert B-cell non-Hodgkin's lymphoma had longer OS and better prognosis than patients with invasive B-cell non-Hodgkin's lymphoma (Figure 2). Among invasive lymphomas, MCL had the worst prognosis (Figure 3) while MALT lymphoma had the best prognosis in inert lymphomas (Figure 4).

\section{MYC Translocation Was Related with Poor Prognosis for PGI-NHL}

Sequential dual-color immunohistochemistry (IHC) assays were performed with the target markers Myc, Bcl2 and Bcl6. The cutoff values for the positivity of BCL6 and MYC were $\geq 40 \%$ and BCL2 $\geq 70 \%$, respectively. For patients with immunostaining positivity, realtime PCR and FISH were conducted to test whether there were translocations. Results showed that 66 patients had MYC translocation, 40 patients had Bcl2 translocation and 48 patients had Bcl6 translocation. Dual translocations of MYC and BCL-2/Bcl-6 were present in 18 patients. MYC translocation and concurrent translocations of MYC and BCL-2/Bcl-6 were associated with inferior OS and PFS both in univariate and multivariate analyses. The OS in the MYC translocation group was significantly shorter than that in the MYC non-translocation group (Figure 5A). The median survival of the MYC 
Table 3 Multivariate Analysis of Factors Influencing Survival in Patients with Primary Gastrointestinal Non-Hodgkin's Lymphoma

\begin{tabular}{|l|l|l|l|l|}
\hline \multirow{2}{*}{ Index } & \multicolumn{2}{l|}{ OS } & \multicolumn{2}{l|}{ PFS } \\
\cline { 2 - 5 } & HR (95\% Cl) & P value & HR (95\% CI) & P value \\
\hline MYC rearrangement & $1.336(0.518,3.448)$ & 0.009 & $1.334(0.426,4.174)$ & 0.021 \\
Pathology & $0.106(0.019,0.577)$ & 0.009 & $0.338(0.038,2.975)$ & 0.328 \\
Sex & $0.840(0.328,2.154)$ & 0.717 & $0.579(0.153,2.198)$ & 0.422 \\
Age & $0.846(0.300,2.384)$ & 0.751 & $0.629(0.117,3.396)$ & 0.590 \\
IPI score & $0.118(0.029,0.480)$ & 0.003 & $0.092(0.012,0.721)$ & 0.023 \\
Ann Arbor stage & $3.831(0.587,25.013)$ & 0.161 & $1.268(0.073,21.980)$ & 0.870 \\
Lugano stage & $0.388(0.076,1.980)$ & 0.255 & $6.959(0.371,130.514)$ & 0.195 \\
Antibacterial & $0.354(0.038,3.274)$ & 0.360 & $0.332(0.021,5.236)$ & 0.434 \\
Rituximab & $0.920(0.371,2.278)$ & 0.856 & $0.273(0.065,1.142)$ & 0.075 \\
Thalidomide & $0.802(0.134,4.790)$ & 0.808 & $1.230(0.168,9.008)$ & 0.839 \\
\hline
\end{tabular}

translocation group was 37.6 \pm 1.6 months, while that of MYC non-translocation group was $54 \pm 1.3$ months $(P<0.05)$. The PFS in the MYC translocation group was also significantly shorter than that in the MYC non-translocation group (Figure 5B, 28.6 \pm 1.8 months vs. $44.8 \pm 2.1$ months, $P<0.05$ ).

\section{Treatment}

Among 219 patients with PGI-NHL, 57 received surgery alone and 32 received chemotherapy, 84 received surgery combined with chemotherapy. Twenty-three patients with HP positive received anti-HP therapy during the course of treatment, of which 7 received anti-HP therapy alone, 5 received anti-HP combined with surgery, 6 received antiHP combined with chemotherapy and 5 received anti-HP combined with radiotherapy (Table 4). We considered other characteristics including age, sex, pathology types, etc. when comparing the prognosis of patients with different treatments. Results showed that simple surgical treatment failed to control the progress of the disease with the PFS was only $5.0 \pm 2.9$ months, while surgery combined with chemotherapy was $29.0 \pm 8.0$ months. There was no significant difference in prognosis between patients received surgery combined with radiotherapy or chemotherapy.

\section{Discussion}

PGIL is the most common form of extranodal NHL. The incidence of males was higher than that of female and the ratio of male to female in our study was 1.35:1. The average age of our cohorts was 56 years old and the median age was 57 years old which was consistent with other studies. ${ }^{1-3}$ The highest incidence was found in people over 55 years of age $(60.3 \%)$, and the lowest incidence was in the age group younger than 20 years old, accounting for $1.4 \%$. Stomach was the most frequently involved site $(63.6 \%)$, followed by small intestinal $(14.6 \%)$ while other parts were rarely involved. $^{4-8}$ Among them, most PGIL were derived from B-cell (93.6\%). The most common pathological types were DLBCL and MALT lymphoma. ${ }^{9-11}$ Furthermore, B-cell lymphoma can be divided into invasive and inert lymphoma. DLBCL, MCL and BL were classified into invasive
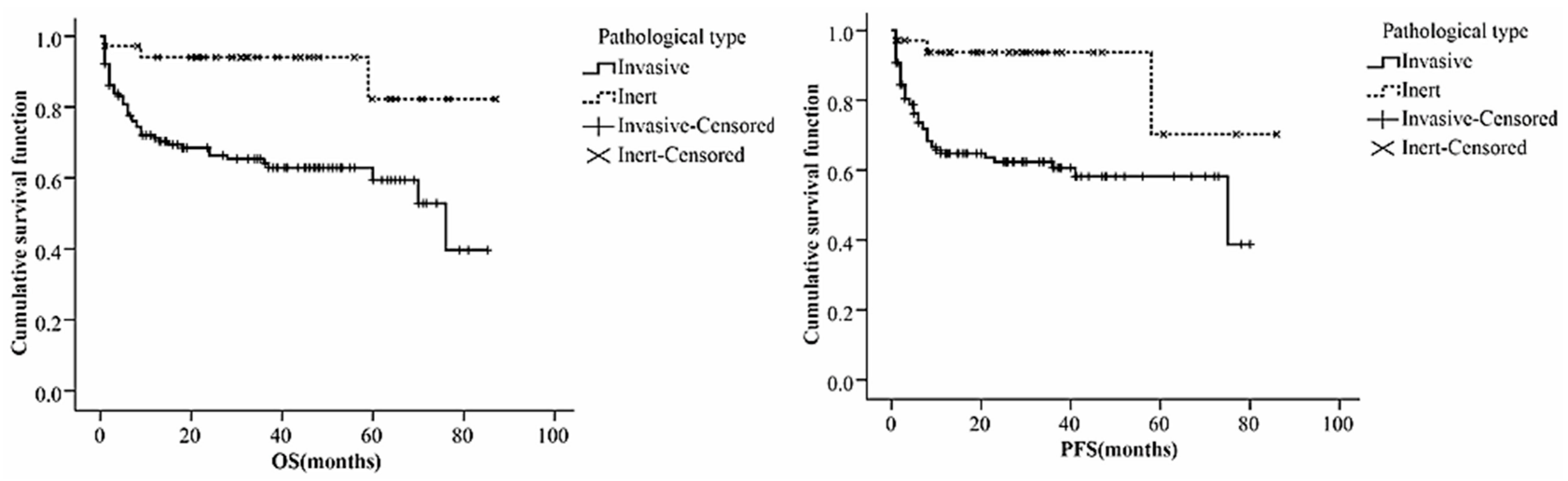

Figure 2 Prognosis of invasive and inert PGIL patients. 



Invasive pathological type

תDLBCL

:MCL

$\therefore \mathrm{BL}$

+ DLBCL-

$\times$ MCL-

Censored

*BL-Censored

Figure 3 Prognosis of different subtypes of invasive PGIL patients.
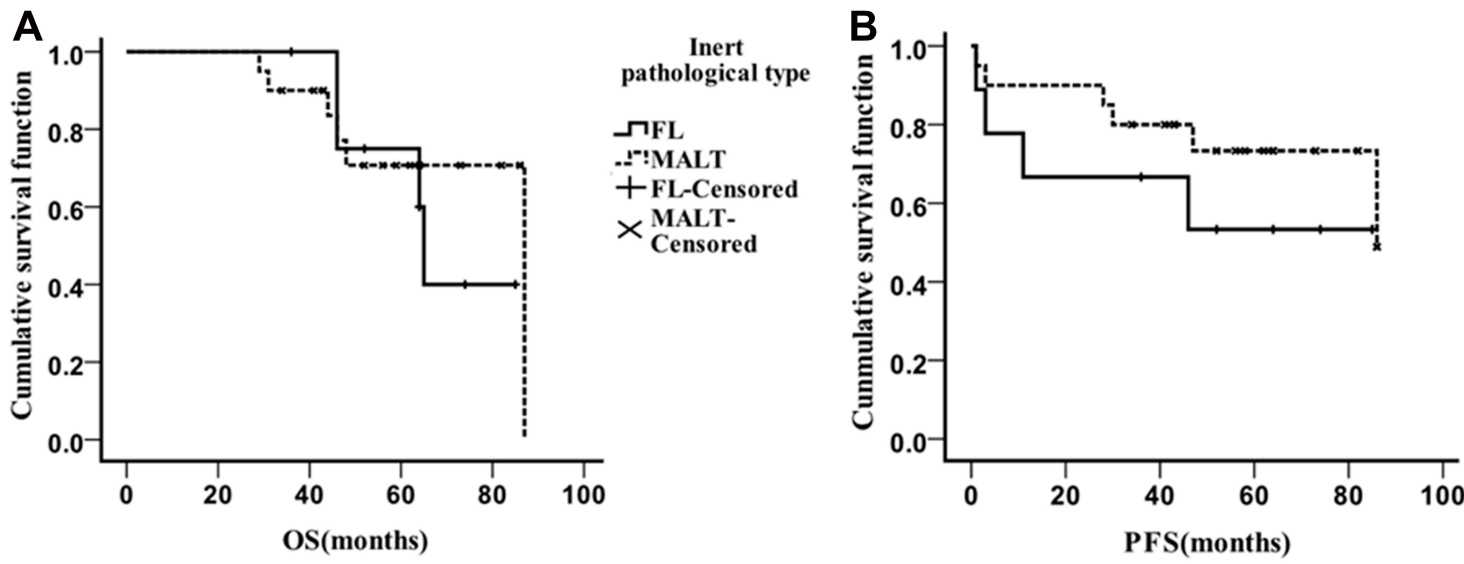

Figure 4 Prognosis of different subtypes of inert PGIL patients. The OS (A) and PFS (B) of patients with inert PGIL such as FL and MALT.


Figure 5 MYC translocation was related to poor prognosis. The OS (A) and PFS (B) of patients with MYC translocation were much shorter than that of patients without MYC translocation.

lymphoma, while inert lymphoma included FL and MALT lymphoma. The OS of patients with invasive lymphoma was shorter than that of patients with inert lymphoma. The prognosis of MCL was worst while MALT lymphoma had the best prognosis.

Besides pathology, it was previously reported that sex, age, IPI score and Ann Arbor staging system were related to the prognosis of lymphomas. ${ }^{10,12,13}$ Besides, some studies reported that lesion location and sources of cells were associated with OS. PGL group had a better OS than that of PIL group. B-cell originated group had a better OS than that of T-cell originated group. Stage I + II group had a better OS than that of stage III + IV group. However, the prognostic factors of PGIL were still unknown. After univariate analysis, pathology, IPI score, MYC translocation and Lugano staging system were involved in the OS and PFS. The results indicated that the OS of B-cell originated lymphoma was longer than that of T-cell 
Table 4 Survival Analysis of Patients with Different Treatment Regimens $(x \pm S D)$

\begin{tabular}{|l|l|l|l|}
\hline Index & Number & $\begin{array}{l}\text { PFS } \\
\text { (Months) }\end{array}$ & $\begin{array}{l}\text { OS } \\
\text { (Months) }\end{array}$ \\
\hline Surgery & 57 & $5.0 \pm 2.9$ & \\
Chemotherapy & 32 & $15.0 \pm 7.2$ & \\
Radiotherapy & 1 & & \\
Surgery+chemotherapy & 84 & $29.0 \pm 20.0$ & \\
Surgery+radiotherapy & 3 & 24.0 & 25.0 \\
Radiotherapy+chemotherapy & 5 & 9.0 & 60.0 \\
Triple combination & 11 & $21.0 \pm 9.0$ & $60.0 \pm 1.1$ \\
Other & 26 & 1.0 & $37.0 \pm 13.1$ \\
\hline
\end{tabular}

originated lymphoma ( $\mathrm{P}=0.009)$. The PFS $(\mathrm{P}=0.023)$ and OS $(\mathrm{P}=0.003)$ of patients with high IPI score were shorter than that of patients with low IPI score. However, PGL group had no significant differences in prognosis compared to PIL group indicating that the location of the disease was not related to prognosis. Multivariate analysis showed that Lugano staging system was not related to prognosis while IPI score, MYC translocation and pathology were associated with OS and PFS. This is the first time to report that MYC rearrangement is associated with poor prognosis of PGIL patients.

The treatment of PGIL is complex and controversial. Surgery was first used as a basic treatment and is now used to treat complications such as intestinal perforation or obstruction. ${ }^{14,15}$ Our results demonstrated that the survival time of patients received only surgery was very short while chemotherapy combined with or without radiotherapy can achieve long-term remission in most patients. Besides, there were no significant differences in prognosis between patients received surgery combined with radiotherapy or chemotherapy. Hence, chemotherapy is envisaged the optimum treatment for PGIL.

R-CHOP (rituximab, cyclophosphamide, adriamycin, vincristine and prednisone) and CHOP-like chemotherapy are the most commonly used first-line treatment. Seventythree cases $(33.3 \%)$ were treated with R-CHOP and 69 cases $(31.5 \%)$ with CHOP. The results showed that there was no significant difference in PFS and OS of patients treated with or without Rituximab, Chidamide and Thalidomide.

\section{Abbreviations}

PGIL, primary gastrointestinal non-Hodgkin lymphoma; PGL, primary gastric lymphoma; PIL, primary intestine lymphoma; OS, overall survival; DLBCL, diffuse large
B-cell lymphoma; MALT, mucosa-associated lymphoid tissue; MCL, mantle cell lymphoma; FL, follicular cell lymphoma; PTCL, peripheral T-cell lymphoma; EATL, enteropathy-associated T-cell lymphoma.

\section{Data Sharing Statement}

The data sets used and/or analyzed during the current study are available from the corresponding author on reasonable request.

\section{Funding}

The study was funded by grants 81670104 from the National Natural Science Foundation of China (NSFC).

\section{Disclosure}

The authors report no conflicts of interest in this work.

\section{References}

1. Ding W, Zhao S, Wang J, et al. Gastrointestinal lymphoma in southwest China: subtype distribution of 1010 cases using the WHO (2008) classification in a single Institution. Acta Haematol. 2016;135(1):21-28. doi:10.1159/000437130

2. Suresh B, Asati V, Lakshmaiah KC, et al. Primary gastrointestinal diffuse large B-cell lymphoma: a prospective study from South India. South Asian J Cancer. 2019;8(1):57-59.

3. Juárez-Salcedo LM, Sokol L, Chavez JC, Dalia S. Primary gastric lymphoma, epidemiology, clinical diagnosis, and treatment. Cancer Control. 2018;25:1-12. doi:10.1177/1073274818778256

4. Ge Z, Liu Z, Hu X, et al. Anatomic distribution, clinical features, and survival data of 87 cases primary gastrointestinal lymphoma. World J Surg Oncol. 2016;14:85. doi:10.1186/s12957-016-0821-9

5. Malipatel R, Patil M, Pritilata Rout P, et al. Primary gastric lymphoma: clinicopathological profile. Euroasian J Hepatogastroenterol. 2018;8(1):6-10. doi:10.5005/jp-journals-10018-1250

6. Castro FA, Jansen L, Krilaviciute A, et al. Survival of patients with gastric lymphoma in Germany and in the United States. J Gastroenterol Hepatol. 2015;30(10):1485-1491. doi:10.1111/jgh.12989

7. Thieblemont C, Cascione L, Conconi A, et al. A MALT lymphoma prognostic index. Blood. 2017;130(12):1409-1417. doi:10.1182/ blood-2017-03-771915

8. Raderer M, Kiesewetter B, Ferreri A. Clinicopathologic characteristics and treatment of marginal zone lymphoma of mucosa-associated lymphoid tissue (MALT lymphoma). CA Cancer J Clin. 2016;66 (2):153-171. doi:10.3322/caac.21330

9. Chen Y, Chen Y, Chen S, et al. Primary gastrointestinal lymphoma: a retrospective multicenter clinical study of 415 cases in Chinese province of Guangdong and a systematic review containing 5075 Chinese patients. Medicine. 2015;94(47):e2119. doi:10.1097/ MD.0000000000002119

10. Shannon EM, MacQueen IT, Miller JM, et al. Management of primary gastrointestinal non-Hodgkin lymphomas: a population-based survival analysis. J Gastrointest Surg. 2016;20(6):1141-1149. doi:10.1007/s11605-016-3129-8

11. Lightner AL, Shannon E, Gibbons MM, et al. Primary gastrointestinal non-Hodgkin's lymphoma of the small and large intestines: a systematic review. J Gastrointest Surg. 2016;20(4):827-839. doi:10.1007/s11605-015-3052-4 
12. Wang $\mathrm{W}$, Lin $\mathrm{P}$, Yao $\mathrm{H}$, et al. Clinical analysis of primary gastrointestinal non-Hodgkin's lymphoma. Pak J Med Sci. 2017;33 (6):1406-1411. doi:10.12669/pjms.336.13631

13. Nagakita K, Takata K, Taniguchi K, et al. Clinicopathological features of 49 primary gastrointestinal diffuse large B-cell lymphoma cases; comparison with location, cell-of-origin, and frequency of MYD88 L265P. Pathol Int. 2016;66:444-452. doi:10.1111/pin.12439
14. Fallone CA, Chiba N, van Zanten SV, et al. The toronto consensus for the treatment of Helicobacter pylori infection in adults. Gastroenterology. 2016;151(1):51-69. doi:10.1053/j.gastro.2016.04.006

15. Brudno JN, Kochenderfer JN. Chimeric antigen receptor T-cell therapies for lymphoma. Nat Rev Clin Oncol. 2018;15(1):31-46. doi:10.1038/nrclinonc. 2017.128

\section{Publish your work in this journal}

OncoTargets and Therapy is an international, peer-reviewed, open access journal focusing on the pathological basis of all cancers, potential targets for therapy and treatment protocols employed to improve the management of cancer patients. The journal also focuses on the impact of management programs and new therapeutic

Submit your manuscript here: https://www.dovepress.com/oncotargets-and-therapy-journal agents and protocols on patient perspectives such as quality of life, adherence and satisfaction. The manuscript management system is completely online and includes a very quick and fair peer-review system, which is all easy to use. Visit http://www.dovepress.com/ testimonials.php to read real quotes from published authors. 